\title{
BMJ Open What is the risk of death or severe harm due to bone cement implantation syndrome among patients undergoing hip hemiarthroplasty for fractured neck of femur? A patient safety surveillance study
}

\author{
Paul D Rutter, ${ }^{1}$ Sukhmeet S Panesar, ${ }^{2}$ Ara Darzi, ${ }^{1}$ Liam J Donaldson ${ }^{1}$
}

To cite: Rutter PD,

Panesar SS, Darzi A, et al. What is the risk of death or severe harm due to bone cement implantation syndrome among patients undergoing hip hemiarthroplasty for fractured neck of femur? A patient safety surveillance study. BMJ Open 2014;4:e004853. doi:10.1136/bmjopen-2014004853

- Prepublication history for this paper is available online. To view these files please visit the journal online (http://dx.doi.org/10.1136/ bmjopen-2014-004853).

Received 14 January 2014 Revised 29 March 2014 Accepted 14 April 2014

CrossMark

For numbered affiliations see end of article.

Correspondence to Dr Paul D Rutter; paul.rutter09@imperial.ac.uk

\section{ABSTRACT}

Objective: To estimate the risk of death or severe harm due to bone cement implantation syndrome (BCIS) among patients undergoing hip hemiarthroplasty for fractured neck of femur.

Setting: Hospitals providing secondary and tertiary care throughout the National Health Service (NHS) in England and Wales.

Participants: Cases reported to the National Reporting and Learning System (NRLS) in which the reporter clearly describes severe acute patient deterioration associated with cement use in hip hemiarthroplasty for fractured neck of femur (assessed independently by two reviewers).

Outcome measures: Primary-number of reported deaths, cardiac arrests and periarrests per year. Secondary-timing of deterioration and outcome in relation to cement insertion.

Results: Between 2005 and 2012, the NRLS received 62 reports that clearly describe death or severe harm associated with the use of cement in hip hemiarthroplasty for fractured neck of femur. There was one such incident for every 2900 hemiarthroplasties for fractured neck of femur during the period. Of the 62 reports, 41 patients died, 14 were resuscitated from cardiac arrest and 7 from periarrest. Most reports (55/62, 89\%) describe acute deterioration occurring during or within a few minutes of cement insertion. The vast majority of deaths $(33 / 41,80 \%)$ occurred on the operating table.

Conclusions: These reports provide narrative evidence from England and Wales that cement use in hip hemiarthroplasty for fractured neck of femur is associated with instances of perioperative death or severe harm consistent with BCIS. In 2009, the National Patient Safety Agency publicised this issue and encouraged the use of mitigation measures. Threequarters of the deaths in this study have occurred since that alert, suggesting incomplete implementation or effectiveness of those mitigation measures. There is a need for stronger evidence that weighs the risks and
Strengths and limitations of this study

- The National Reporting and Learning System (NRLS) receives data from a health service serving 56 million people, so it is able to detect patterns of rare but serious harm not apparent to individual practitioners or even within formal trials.

- Reports to the NRLS provide narrative accounts of bone cement implantation syndrome (BCIS) from first-hand witnesses, adding to the weight of evidence that this condition exists and is causing death and severe harm.

- The NRLS suffers from under-reporting, so an estimate of $\mathrm{BCIS}$ incidence derived from it is probably an underestimate and the magnitude of this effect is difficult to assess.

- The NRLS is not designed to completely assess the benefits and risks of a treatment and its alternatives, so this study's findings must be considered in conjunction with other sources that provide information on benefits associated with cement use, and on all-cause mortality associated with cemented and uncemented hip hemiarthroplasty.

benefits of cement in hip hemiarthroplasty for fractured neck of femur.

\section{INTRODUCTION}

In 2012, more than 22000 people in the UK had a hemiarthroplasty following fractured neck of femur. ${ }^{1}$ In each of these operations, the surgeon may use cement to help hold the prosthesis in place. There is extensive debate about the pros and cons of doing so, and considerable international variation in 
this practice. ${ }^{2}$ Almost 75000 hip fractures (proximal femoral fractures) occur annually in the UK, with a combined medical and social care cost amounting to about $£ 2$ billion a year. The incidence of these fractures is likely to increase. Usually hip fractures are 'fragility' fractures caused by a fall affecting older people with preexisting bone pathology (osteopenia or osteoporosis). ${ }^{3}$

In 2003, the National Health Service (NHS) in England and Wales established a patient safety incident reporting system, called the National Reporting and Learning System (NRLS). ${ }^{4}$ It was designed and initially managed by an independent agency-the National Patient Safety Agency (NPSA). Staff throughout the NHS were, and still are, encouraged to report any unintended or unexpected incident that led to patient harm, or could have done so. ${ }^{5}$ Nine million reports have been received until now, ${ }^{6}$ making the NRLS the largest repository of patient safety incidents in the world.

In 2009, the NPSA became concerned about the accumulation of incident reports attributing the use of cement in hip surgery (specifically, hemiarthroplasty for fractured neck of femur) to sudden death and severe harm. ${ }^{7}$ These reports seemed to denote the previously described phenomenon of bone cement implantation syndrome (BCIS). This involves venous embolisation of fat and marrow contents caused by instrumentation of the femoral canal and particularly cement insertion, leading to hypotension, hypoxia and/or cardiac arrest. The aetiopathogenesis of BCIS is poorly understood. Some of the proposed mechanisms involve the release of methyl methacrylate cement monomers into the circulation following high pressures generated during cementation. Immunological mechanisms such as histamine release, complement activation and endogenous cannabinoid-mediated vasodilation at the time of cement insertion have also been implicated. ${ }^{89}$

After extensive discussion with relevant professional bodies, guidance was issued by the NPSA to the NHS. ${ }^{10}$ This drew attention to the cluster of incidents and to the variation in international orthopaedic practice. The guidance advised extra precautions in the use of cement, to do with appropriate patient assessment, anaesthetic technique and surgical technique (figure 1). The lack of a firm direction not to use cement reflected both the absence of definitive research evidence of risk and professional opinion that doubted the numerical importance of the problem. ${ }^{10}$

Since the national alert was issued, a number of research reports, mostly meta-analyses of randomised controlled trials (RCTs), have suggested that there is no net increased risk from cement. ${ }^{11-14}$ However, increasing numbers of patient safety incident reports from the NHS have continued to give stark accounts of the proximity of cement insertion in hip operations to sudden death. The NRLS is a unique repository of such information. In this study, we examine the series of incident reports made to the NRLS on this topic and consider the implications for clinical policy and patient safety.

\section{METHODS}

Since 2004, staff from all parts of the NHS have been encouraged to make an incident report of any situation in which they believe that a patient's safety has been compromised. A 'patient safety incident' is defined as: 'Any unintended or unexpected incident which could have, or did, lead to harm for one or more patients receiving NHS care. $^{15}$ Clinical or other staff initially report incidents to the patient safety reporting system in the hospital or other organisation where they work. Subsequently, the reports are anonymised through the removal of personal identifiers and forwarded to the NRLS to allow for national-level analysis. Members of the public are also able to report incidents directly to the NRLS through an online form. The information fields in each incident report cover: demographic and administrative data; the circumstances of occurrence; a categorisation of causation; an assessment of the degree of harm into 'no', 'low', 'moderate', 'severe' or 'death' and action taken or planned to investigate or prevent a recurrence. These data are captured in a structured reporting form. There is also a section of free text where the reporter is asked to describe what happened and why they think it happened. The structure of the database has been described in detail elsewhere. ${ }^{16}$

We searched the NRLS database for reports made between 1 January 2005 and 31 December 2012, in which the free-text field contained: 'cement' OR ( ('death on operating table' or 'death on table' or 'died on operating table' or 'intraoperative death' or 'cardiac arrest' or 'desaturation' or 'hypotension' or 'fat embolus' or 'fat embolism' or 'collapse') AND ('orthopaedic surgery' or 'orthopaedic operation' or 'hip surgery' or 'hip operation' or 'hip replacement' or 'arthroplasty' or 'hemiarthroplasty' or 'intramedullary')). This search was applied to reports classified as 'death', 'severe harm' or 'moderate harm' (the latter was included because there are instances of death being mistakenly reported as 'moderate harm', for example). Data collected during the first year of operation of the NRLS (2004) are not used because this is regarded as a development phase.

Two researchers (PDR and SSP) independently assessed the free-text descriptions provided within retrieved reports. Each reviewer assessed whether or not the report described, as its primary purpose, an acute patient deterioration (immediately leading to death or not) during or shortly after the insertion of cement in hip hemiarthroplasty for fractured neck of femur. Inter-rater agreement between reviewers was calculated, and differences were resolved through arbitration by a third reviewer (LJD).

Further data were extracted from each included report: year of report, operation type, indication for surgery, patient age, outcome (death, cardiac arrest or periarrest). In addition, the timing of both the acute deterioration and the outcome were separately categorised based on the information provided in the 
Figure 1 Measures to mitigate risk of bone cement implantation syndrome advised by the National Patient Safety Agency 2009 alert.

Patient assessment
- Identify patients at risk (e.g. those with pre-existing cardiopulmonary dysfunction),
assess fitness for surgery and most appropriate technique
Anaesthetic technique
- Maintain normovolemia throughout the procedure, particularly prior to cement
insertion
- Maintain particular vigilance during instrumentation and fixation of the implant
Surgical technique
- Thorough pressurised lavage of the femoral canal before broaching the canal and
further instrumentation of the femur
- Consider a suction catheter to reduce the pressure in the intramedullary canal
- Introduce cement into the femur in retrograde fashion via a cement gun
- Communicate with the anaesthetist regarding when cement is to be inserted

Patient assessment assess fitness for surgery and most appropriate technique

Anaesthetic technique

Maintain normovolemia throughout the pr

Maintain particular vigilance during instrumentation and fixation of the implan Surgical technique

further instrumentation of the femur

Communicate with the anaesthetist regarding when cement is to be inserted

free-text description. If any description suggested an alternative or major contributing cause of death, this was recorded. Each report was also categorised as a 'pre-NPSA alert' (1 January 2005 to 14 September 2009) or a 'post-NPSA alert' (15 September 2009 to 31 December 2012). The cut-off date, 14 September 2009, was the implementation deadline for the NPSA alert.

Data were recorded in Microsoft Excel 2011 and analysed in Stata V.12. Significance tests are two-tailed. This study was part of a research programme funded at Imperial College by NHS England to develop incident reporting in the NHS.

\section{RESULTS}

A total of 360 reports met the search criteria and were examined in detail. Of these, 62 were judged by the reviewers to describe death or severe harm associated, in the description provided by the reporter, with the use of cement in hip hemiarthroplasty for fractured neck of femur. Two-thirds of these $(41 / 62,66 \%)$ described deaths. A further 14 described cardiac arrests from which the patient was resuscitated, and another seven described periarrest situations from which the patient recovered. Inter-rater agreement was very high $(\mathrm{k}=0.962$, $\mathrm{p}<0.0001)$. The number of such reports generally increased year on year during the period (figure 2).
A further 39 reports described death or severe harm associated with the use of cement in a different hip operation $(n=12)$, or in a hip operation in which the operation type or indication (or both) was not stated in the report $(n=27)$.

The sensitive search strategy also yielded 259 reports that were discarded because they did not describe death or severe harm associated with the use of cement in any hip operation. Most described minor errors associated with the preparation and use of cement, such as unavailability of cement or poor knowledge of cement preparation. Others related to hip surgery but not to cement, or to surgery involving other joints.

The most common descriptions were that the acute deterioration occurred 'during cement insertion' (24/ $62,39 \%$, table 1) or 'after cement insertion' (16/62, $26 \%)$. Including these, the great majority of descriptions $(55 / 62,89 \%)$ suggested that deterioration occurred within approximately $3 \mathrm{~min}$ of cementation ('shortly after' in six cases, 'during prosthesis insertion' in two cases, 'within 1 min' in three cases and 'within 2-3 min' in four cases). In the remainder, the deterioration occurred later but before the end of the operation. A representative sample of anonymised descriptions is provided in figure 3 .

All of the reported cardiac arrests and periarrests occurred immediately, on the operating table. The
Figure 2 Deaths, cardiac arrests and periarrests related to hip cement among patient safety incident reports in England and Wales, 2005-2012.

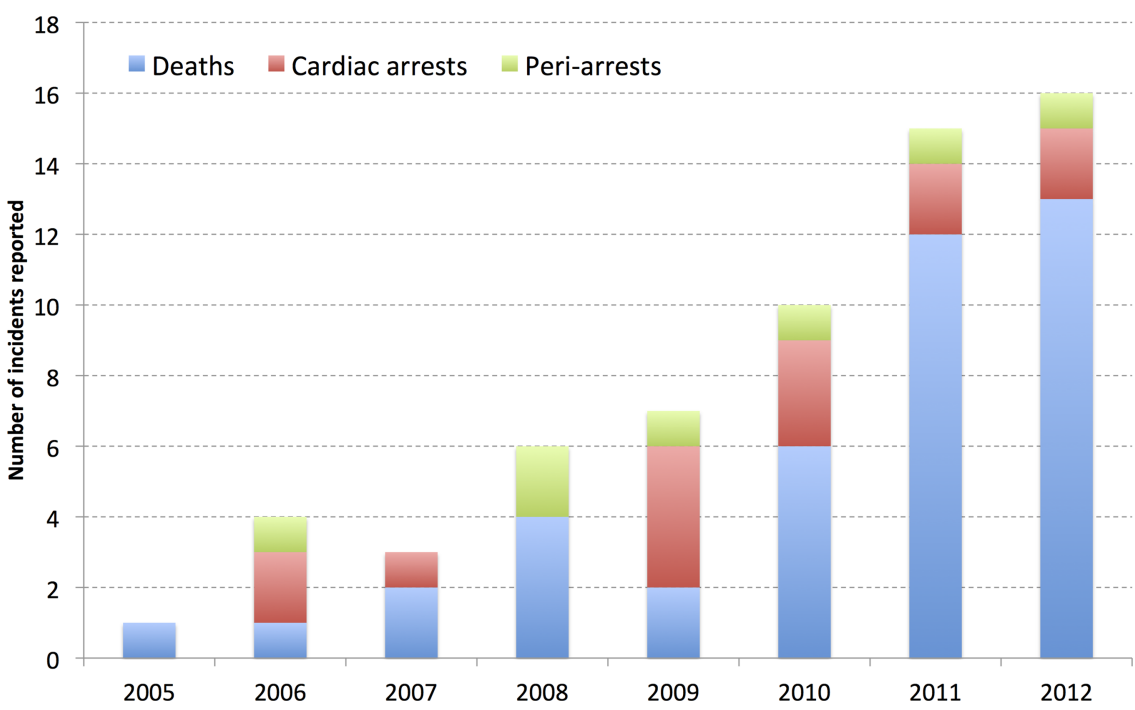


Table 1 Timing of acute deterioration, as described in the free-text section of the patient safety incident reports

\begin{tabular}{lrr}
\hline $\begin{array}{l}\text { Deterioration described } \\
\text { to have occurred }\end{array}$ & \multicolumn{2}{c}{$\begin{array}{c}\text { Number of } \\
\text { reports (\%) }\end{array}$} \\
\hline During cement insertion & 24 & 39 \\
Shortly after cement insertion & 6 & 10 \\
After cement insertion & 16 & 26 \\
During prosthesis insertion & 2 & 3 \\
After prosthesis insertion & 1 & 2 \\
At closing & 1 & 2 \\
Within 1 min of cement insertion & 3 & 5 \\
2-3 min after cement insertion & 4 & 6 \\
4-6 min after cement insertion & 3 & 5 \\
7-15 min after cement insertion & 2 & 3 \\
Total & 62 & 100 \\
\hline
\end{tabular}

majority of the deaths $(33 / 41,80 \%)$ also occurred on the table. In the remainder, the acute deterioration started as described above, but the patient did not die until later.

The reports referred to patients aged between 66 and 100 years. The median age was 88 and the mean 87 (SD 7 years). Mean age did not differ significantly by outcome (87.4 years among deaths, 84.5 years among cardiac arrests, 88.5 years among periarrests, $\chi^{2}=1.722$, $\mathrm{p}=0.423$ ).

Nearly three times as many reports were made in the 39.5 months after the NPSA alert was issued than in the 56.5 months before it (46 vs 16 , table 2). The increase in reports was more marked for deaths (3.6-fold) than for cardiac arrests (2.4-fold) and periarrests (1.3-fold).

In addition to the 62 cases already described, 39 other reports also clearly described deterioration leading to death, cardiac arrest or periarrest associated with cement use during a hip operation. These were not included in the main analysis because they did not state that the operation described was hemiarthroplasty for fractured neck of femur. In just under one-third of these reports $(12 / 39,31 \%)$, the operation was clearly not a hemiarthroplasty (three total hip replacements for fractured neck of femur, five total hip replacements with no indication given, four non-arthroplasty hip operations). The majority $(27 / 39,69 \%)$, however, were not included but might have related to hemiarthroplasty for fractured
Table 2 Patient safety incident reports involving hip cement occurring before and after a national alert was issued advising precautions when using cement

\begin{tabular}{lccc}
\hline & \multicolumn{3}{l}{ Number of reports } \\
\cline { 2 - 4 } Outcome & Prealert & Postalert & Total \\
\hline Death & 9 & 32 & 41 \\
Cardiac arrest & 4 & 10 & 14 \\
Periarrest & 3 & 4 & 7 \\
All outcomes & 16 & 46 & 62 \\
\hline
\end{tabular}

neck of femur. In 11 reports, the operation was not stated but the indication was stated as fractured neck of femur. In the other 16 reports, neither the operation nor the indication was specified (except to describe a hip operation involving cement). If some or all of these 27 reports were in fact of hemiarthroplasties for fractured neck of femur, this would increase the count reported in this paper from 62 cases potentially up to 89 , an increase of up to $44 \%$.

\section{DISCUSSION}

This paper presents a series of 62 cases of deaths or severe harm associated, in reports to the NRLS, with the use of cement during hip surgery. These occurred in England and Wales between 2005 and 2012. Among these there were 41 deaths, 14 patients who suffered a cardiac arrest but survived, and 7 who suffered a periarrest but survived. With a total of 180000 hemiarthroplasties for fractured neck of femur carried out in this period, one report of death or serious harm was received for every 2900 cases.

The value of this paper derives from the major strength of the NRLS - that it receives reports of adverse events from across a health service serving 56 million people. The NRLS can therefore detect patterns of rare but serious harm that may not be apparent to individual practitioners or hospitals, or indeed within formal trials. Most reports contain a free-text description of the incident. We are therefore able to present a series of cases highly suggestive of BCIS, with the compelling descriptions provided by first-hand witnesses adding to the weight of evidence that, though its incidence is rare, this
Figure 3 Examples of extracts from included patient safety incident reports.
"During cementing of femoral component the patient suffered a cardiac arrest. Resuscitation commenced. Re-arrested twice more. Patient pronounced dead.“

"When the cement went in, the systolic BP fell to $50 \mathrm{mmHg}$ and she stopped breathing."

"Uneventful anaesthetic until cementing followed by immediate asystolic cardiac arrest."

"Soon after cementing patient dropped blood pressure and lost output." 
condition exists and is causing instances of death and severe harm.

This study has two main weaknesses. First, the NRLS suffers from under-reporting. The number of cases of BCIS presented here probably under-represents its true incidence, and the magnitude of this effect is difficult to assess. Second, the NRLS is not designed to offer a complete assessment of the benefits and risks of a treatment and its alternatives. Our findings need to be considered in conjunction with other sources that can provide information on the benefits associated with cement, and on all-cause mortality associated with cemented and uncemented surgery.

The accumulation of these reports earlier led to considerable concern at the NPSA, which in 2009 issued an alert to the NHS about the issue. This alert advised anaesthetic and surgical measures to mitigate the risk of BCIS, rather than advising that cement should not be used. This was despite the fact that uncemented prostheses are the norm in some countries, and also because there was a lack of professional consensus in England and Wales on the research evidence of risk and on the size of the problem.

Since the NPSA alert was issued, a number of meta-analyses have pooled RCT data to compare mortality between cemented and uncemented hemiarthroplasty in the treatment of hip fracture. ${ }^{11-14}$ These meta-analyses are severely limited by their small size. By our calculation, even the largest of them, ${ }^{12}$ with data from just 1175 participants, only had sufficient statistical power to detect a mortality difference if hip cement was causing one additional death for every 25 patients treated (based on standard power calculation variables $\alpha=0.1$ and $\beta=0.8$, and mortality among the uncemented group of $6 \%$ ). To detect even a difference of 1 additional death per 100 patients would require a 15000 participant study. It should therefore come as no surprise that none of these meta-analyses has found a statistically significant mortality difference, but this does not demonstrate that there is no clinically significant difference. In our view, these studies have been widely taken to be more conclusive than they actually are.

A number of countries have well-established joint replacement registries. Their substantial size makes these a potentially useful source of data to address questions such as this. However, the National Joint Registry for England, Wales and Northern Ireland ${ }^{17}$ collects data on total hip replacement only, not on the hemiarthroplasties with which most of the deaths described here are associated.

Analysis of 25000 hemiarthroplasties recorded in the Australian registry found that cement use was associated with a higher mortality rate at 1 day postoperatively, but the reverse was found at 1 week, 1 month and 1 year. ${ }^{18}$ Conversely, an analysis of the UK National Hip Fracture Database found use of cement to be associated with a small but significant adjusted survival benefit (adjusted OR $0.83,95 \%$ CI 0.72 to 0.96$).{ }^{19}$ This was based on data from 16496 cases in 129 hospitals over the course of a year. It captures all causes of in-hospital mortality, and the result is adjusted for gender, age, type of surgery and ability to walk outdoors unaccompanied. However, the authors admit "concern about the "completeness" of the data submitted to the database: the figures are improving, but few hospitals submit data on all their patients with a fracture of the proximal femur'. In such circumstances, it seems very reasonable to suppose that patients who die intraoperatively might be less likely to have their data submitted than patients who do not. If so, this bias means that cases of BCIS-related death may have been missed and the risks associated with cement use underestimated.

The most recent registry-based analysis comes from Norway. ${ }^{20}$ Based on 11000 patients, it finds cement use to be associated with a substantially higher mortality rate within the first day postoperatively-1 additional death per 116 operations among cemented than uncemented arthroplasties. This analysis is able to adjust for underlying differences between groups, but it suffers from some degree of missing data.

The registries are likely to provide further valuable information on this question, but because they allow observational, rather than randomised, studies, it will be vital to remove potential reporting biases and to collect sufficient information to allow for case-mix adjustment.

The patient safety incident reports detailed in this paper are compelling, representing eyewitness accounts of instances in which bone cement seems to have caused death or severe harm. The NRLS and patient reporting systems, in general, are relatively new. Such systems offer a unique source of learning from errors at the local, national or international level. ${ }^{21}$ There is no consensus about how their data should be weighed alongside established sources. For example, the current National Institute for Health and Clinical Excellence (NICE) hip fracture guideline ${ }^{22}$ cites the small meta-analyses and RCTs referred to above, states that there is no evidence of mortality difference, and so recommends the use of cement. It takes no account of NRLS data, or indeed of registry-based studies. Patient safety incident reports tend to be undervalued, mainly because there is underreporting, but this is only likely to underestimate the extent of a problem, not to overstate it. Such reporting systems may by the only source powerful enough to pick up a 'signal' when there is a rare cause of harm.

Even allowing for under-reporting, the data presented here suggest that BCIS is a rare event. It might well be the case that cement provides a benefit to patients that outweighs the harm of BCIS. For example, individual studies have associated uncemented hip hemiarthroplasty with a greater number of mechanical complications $^{23}$ and reoperations, ${ }^{24}$ and a decline in this technique has been noticed in some countries. ${ }^{25}$ However, it is not straightforward to assert that cement provides greater benefit than uncemented replacement. The considerable international variation in the use of 
cement illustrates this uncertainty. The recent NICE guideline on hip fracture finds that the evidence on this question is of low or moderate quality. It concludes that cement use has a statistically significant benefit in terms of mobility and pain, but that the scale of this benefit is not clinically significant.

Three-quarters of the cases in this study have occurred since the NPSA issued its 2009 alert, advising surgical and anaesthetic measures to mitigate the risk of BCIS. ${ }^{10}$ The fact that the reported numbers have increased does not necessarily mean that the true mortality rate has increased. The 2009 alert advised that all cases of death and severe harm associated with cement should be reported. Also, since 2010, it has been compulsory in the NHS to report any death associated with a patient safety concern, whereas this was previously voluntary. Further, the number of reports received by the NRLS on all participants has increased year on year. The fact that deaths have continued clearly shows that the implementation of mitigation measures set out in the alert was suboptimal, or that their effectiveness is suboptimal, or both. Patient safety incident reporting systems have been criticised for weaknesses in cascading their learning to frontline staff, ${ }^{26}$ and it is unclear what effect national patient safety alerts have on the delivery of safer care. ${ }^{27}$

This study suggests that BCIS continues to cause rare instances of death and severe harm in emergency hip hemiarthroplasty surgery in England and Wales, despite a 2009 national alert that advised on best practice measures to mitigate this risk. This study should serve to reinforce the importance of taking the anaesthetic and surgical measures known to mitigate the risk of BCIS.

This study suggests that the risk is one death or severe harm per 2900 cases, although this conclusion is limited by under-reporting. Although rare, BCIS contributes to the total mortality associated with cemented hip hemiarthroplasty surgery. To provide a definitive answer to the question of whether cement causes net benefit or net harm, there is a need for registry-based studies that achieve complete ascertainment of cases and gather sufficient information to enable the case-mix to be adjusted for (which the currently available registry-based studies do not), or for multicentre, expertise-based randomised trials that are sufficiently powered to detect clinically important differences in mortality rate (which the currently available meta-analyses of RCTs are not). ${ }^{28}$

More generally, this study demonstrates the value of patient safety incident reports in examining causes of harm that may not be detected even by studies high within the hierarchy of traditional research evidence. There is a need for more work on how data from studies such as this one should be considered in tandem with the findings of more traditional studies to optimally answer complex patient safety questions.

\footnotetext{
Author affiliations

${ }^{1}$ Institute of Global Health Innovation, Imperial College London, London, UK ${ }^{2}$ Department of Primary Care and Public Health, Imperial College London, London, UK
}

Contributors Data analysis was undertaken by PDR and SSP. The paper was drafted by PDR and SSP and critically reviewed by AD and LJD. All authors contributed to the conception and design of this work. All authors approved the final version.

Funding This study was part of a research programme funded at Imperial College by National Health Service (NHS) England to develop incident reporting in the NHS.

\section{Competing interests None.}

Ethics approval This study was part of a research programme funded at Imperial College by NHS England to develop incident reporting in the NHS. Ethical approval is in place for this programme from the Health Research Authority.

Provenance and peer review Not commissioned; externally peer reviewed.

Data sharing statement No additional data are available.

Open Access This is an Open Access article distributed in accordance with the Creative Commons Attribution Non Commercial (CC BY-NC 3.0) license, which permits others to distribute, remix, adapt, build upon this work noncommercially, and license their derivative works on different terms, provided the original work is properly cited and the use is non-commercial. See: http:// creativecommons.org/licenses/by-nc/3.0/

\section{REFERENCES}

1. National Hip Fracture Database. National Report 2013. http://www. nhfd.co.uk/003/hipfractureR.nsf/resourceDisplay?openform (accessed 21 Nov 2013).

2. Panesar SS, Cleary K, Bhandari M, et al. To cement or not in hip fracture surgery? Lancet 2009;374:1047-9.

3. British Orthopaedic Association. The care of patients with fragility fractures. (Guideline Ref ID: BOA2007). 2007.

4. Williams SK, Osborn SS. The development of the national reporting and learning system in England and Wales, 2001-2005. Med J Aust 2006;184:S65

5. NHS National Reporting and Learning System. About reporting patient safety incidents. http://www.nrls.npsa.nhs.uk/report-a-patient-safetyincident/about-reporting-patient-safety-incidents (accessed 21 Nov 2013)

6. NHS National Reporting and Learning System. NRLS quarterly data workbook up to December 2012. http://www.nrls.nhs.uk/resources/ collections/quarterly-data-summaries/?entryid45=135213 (accessed 21 Nov 2013).

7. National Patient Safety Agency. Mitigating surgical risk in patients undergoing hip arthroplasty for fractures of the proximal femur. National Patient Safety Report; 2009, NPSA/2009/RRR001. ttp://www.nrls.npsa. nhs.uk/resources/?Entryld45=59867 (accessed 21 Nov 2013).

8. Donaldson AJ, Thomson HE, Harper NJ, et al. Bone cement implantation syndrome. Br J Anaesth 2009;102:12-22.

9. Motobe T, Hashiguchi T, Uchimura T, et al. Endogenous cannabinoids are candidates for lipid mediators of bone cement implantation syndrome. Shock 2004;21:8-12.

10. Timperley AJ, Whitehouse SL. Mitigating surgical risk in patients undergoing hip arthroplasty for fractures of the proximal femur. $J$ Bone Joint Surg 2009;91-B:851-4.

11. Azegami S, Gurusamy KS, Parker MJ. Cemented versus uncemented hemiarthroplasty for hip fractures: a systematic review of randomised controlled trials. Hip Int 2001;21:509-17.

12. Luo XP, He SQ, Li ZA, et al. Systematic review of cemented versus uncemented hemiarthroplasty for displaced femoral neck fractures in older patients. Arch Orthop Trauma Surg 2012;132:455-63.

13. Li T, Zhuang Q, Weng X, et al. Cemented versus uncemented hemiarthroplasty for femoral neck fractures in elderly patients: a meta-analysis. PLoS ONE 2013;8:e68903.

14. Parker MJ, Gurusamy KS, Azegami S. Arthroplasties (with and without bone cement) for proximal femoral fractures in adults. Cochrane Database Syst Rev 2010;6:CD001706.

15. National Patient Safety Agency. What is a patient safety incident? http://www.npsa.nhs.uk/nrls/reporting/ what-is-a-patient-safety-incident (accessed 29 Nov 2013).

16. Panesar SS, Salvilla SA, Patel B, et al. Laparoscopic cholecystectomy: device-related errors revealed through a national database. Expert Rev Med Devices 2011;8:555-60.

17. National Joint Registry for England, Wales and Northern Ireland. 10th Annual Report 2013. http://www.njircentre.org.uk/njrcentre/ Reports,PublicationsandMinutes/Annualreports/tabid/86/Default.aspx (accessed 21 Nov 2013). 
18. Costain DL, Whitehouse SL, Pratt NL, et al. Perioperative mortality after hemiarthroplasty related to fixation method: a study based on the Australian Orthopaedic Association National Joint Replacement Registry. Acta Orthop 2011;82:275-81.

19. Costa ML, Griffin XL, Pendleton N, et al. Does cementing the femoral component increase the risk of peri-operative mortality for patients having replacement surgery for a fracture of the neck of femur? Data from the National Hip Fracture Database. J Bone Joint Surg 2011;93-B:1405-10.

20. Talsnes O, Vinje T, Gjertsen JE, et al. Perioperative mortality in hip fracture patients treated with cemented and uncemented hemiprosthesis: a register study of 11210 patients. Int Orthop 2013;37:1135-40.

21. Noble DJ, Panesar SS, Pronovost PJ. A public health approach to patient safety reporting systems is urgently needed. $J$ Patient Saf 2011;7:109-12.

22. National Clinical Guideline Centre. The management of hip fracture in adults. London: National Clinical Guideline Centre, 2011. http:// www.ncgc.ac.uk (accessed 21 Nov 2013)
23. Yli-Kyyny $\mathrm{T}$, Sund $\mathrm{R}$, Heinänen $\mathrm{M}$, et al. Cemented or uncemented hemiarthroplasty for the treatment of femoral neck fractures? Acta Orthop 2014;85:49-53.

24. Leonardsson O, Kärrholm J, Åkesson K, et al. Higher risk of reoperation for bipolar and uncemented hemiarthroplasty. Acta Orthop 2012;83:459-66.

25. Leonardsson O, Garellick G, Kärrholm J, et al. Changes in implant choice and surgical technique for hemiarthroplasty. 21,346 procedures from the Swedish Hip Arthroplasty Register 2005-2009. Acta Orthop 2012;83:7-13.

26. Panesar SS, Cleary K, Sheikh A. Reflections on the National Patient Safety Agency's database of medical errors. J R Soc Med 2009;102:256-8.

27. Lankshear A, Lowson K, Weingart SN. An assessment of the quality and impact of NPSA medication safety outputs issued to the NHS in England and Wales. BMJ Qual Saf 2011;20:360-5.

28. Devereaux PJ, Bhandari $M$, Clarke $M$, et al. Need for expertise-based randomised controlled trials. $B M J$ 2005;330:88. 